\title{
Language policy in Chinese higher education: A focus on international students in China
}

\author{
Ying Wang \\ University of Southampton \\ (ying.wang@soton.ac.uk)
}

\begin{abstract}
This paper is motivated by the observation that relatively little research has been done to investigate language policy in Chinese higher education oriented towards international students, in the context that China welcomes an increasing number of international students in its higher education sector in response to globalisation. The paper integrates Spolsky's (2012) three-component framework of language policy with Ricento and Hornberger's (1996) approach that examines language policy in multiple levels. It also considers the implications for language policy of research into English as a lingua franca. Empirical data are collected through document analysis, interviews and classroom observation to explore what language policies are available to support Chinese higher education for international students and how language policies are operationalised in institutional settings, with a focus on one university for case study. The investigation reveals a policy vacuum in Chinese higher education for international students, leading to the discussion of ways of addressing the vacuum in the conclusion.
\end{abstract}

\section{Introduction}

As globalisation gives rise to the mobility of students on a global scale, China is developing into a provider of international education, attracting international students from other countries. Statistics released from the Ministry of Education (MoE) (unknown, 2016) shows that there were 61,869 students from 169 countries studying in China in 2001, while, in comparison, China received more than 397,635 international students in 2015. The MoE has initiated the Plan for Study in China project under the National Outline for Medium and Long-term Education Reform and Development (20102020). The Plan defines one of its objectives as developing China 'into the country with the largest number of international students in Asia' (China Scholarship Council 2012). Correspondingly, the Plan sets a target to get 500,000 international students enrolled in the Chinese education system, which include 150,000 international students enrolled in degree programmes in Mainland China by 2020 (ibid.). The dramatic growth of the international student population in China and the goal to attract further more international students to China, however, contrast with the lack of research on language policy in Chinese higher education oriented towards international students in China.

An overview of the research on language policy in China reveals a focus on Chinese student population in Chinese education. There are three major strands of language policy research in China according to language choices, that enter scholarly debates regarding why some languages are promoted through education as a mechanism while others are not. The first strand aligns with multilingualism in Chinese society, discussing the relationship between Chinese Han and other languages used by minority ethnic groups as their mother tongues in the discourse of national education (e.g. Zhou and Sun 2004). Attention is paid to recurring issues such as Chinese standardisation, minority ethnic groups' language rights and identities. The second strand is contextualised by the national recognition of the role of English in modernisation and focused on English education policy in particular (e.g. Hu 2001, Hu 2005, Pan 2011). As Wang and Gao (2008: 236) point out, most studies 
address 'a consistent concern' with 'how to implement an effective English language curriculum for national and social advance in a context of enormous size and ethnic diversity'. The discussion often engages with numerous English education and testing reforms that have been carried out in order to develop university students' English proficiency and to regulate professionals' qualifications. Apart from the neutral position, a critical approach is adopted. Hu (2005) problematises English language education policies for causing social inequality. Pan (2011) criticises Chinese authorities for using English-focused foreign language education policies for the purposes of political and cultural governance so as to achieve hegemony within China. The third strand addresses the extension of mania for English to various disciplinary fields and discusses English medium instruction (EMI) in Chinese society. Hu and Alsagoff (2010) have summarised four types of EMI in China, drawing upon various publications of studies and debates on EMI in this country. The four types are classified in terms of the allocation of English and Chinese in classroom activities. The more reliance on Chinese is associated with the less educational resources; the more reliance on English is associated with the more educational resources. The four types therefore reflect the socio-economical stratification in Chinese society (Hu and Alsagoff 2010). The overview thus points to an overlooked area of language policy research in relation to international students in Chinese education institutions. Needless to say language policy research focusing on international students in Chinese higher education is even more rare.

Nonetheless, language policy is a significant issue for individual students — not only mother tongue students but also international students - having impacts on students' learning outcomes, experiences, and identities. While previous research on international students in other contexts - e.g. Jenkins (2014) on British university and Mauranen (2012) on Finland university - can offer some reference in understanding issues with regard to medium of instruction for international students, language policy as a socially constructed concept needs to be understood in particular contexts where it is applicable and where individual students are situated. Understanding language policy in relation to international students in China is thus necessary. The inquiry can provide insights into international students' education situation in China and can offer reference to policy evaluation and suggestion in China.

To this end, this paper explores what language policies are oriented towards international students in Chinese higher education by examining available documents engaging this field nationally and institutionally. It also investigates how language policies are operationalised in particular institutions, with a focus on one university through case study. The study leads to an argument that currently there is a lack of appropriate language policy to support international students' education experience. This paper thus calls for a recognition of the role of English as a lingua franca in international education and for the development of support for EMI programmes so as to address international students' needs and wants as well as the language needs and disciplinary interests of teaching staff.

\section{Background}

China, like many other countries, is keen on higher education internationalisation in response to the momentum of globalisation. Providing international students with Chinese higher education is one of many initiatives that the MoE encourages. Relevant regulations and documents are issued for the purpose of international education management. The China Scholarship Council is subordinate to the MoE and runs the Study in China website, which claims to be 'authoritative, comprehensive, instructive' and provides guidelines relevant to international students' study in China. The website lists universities that have been recognised by the MoE as qualified to recruit international students 
and university programmes that are available for international students.

The university for case study is located in Yichang, a middle-scale city renowned for its hydroelectric industry and tourism industry not only nationally but also internationally. It is one of the listed universities on the Study in China website. As the website notes,

[The university] was awarded with "Advanced unit of opening up" by Hubei Provincial government in 2010; and was awarded with "Demonstration base of international student education" in 2014.

The university as a first-tier university is proud of its strong position in providing international programmes oriented towards international students. In the Letter from the President in the Prospectus for International Students, the university is described as 'a multi-cultural campus environment' which has provided higher education to over 1000 international students. The Letter makes explicit its achievement as evaluated within Chinese higher education system:

We are awarded "Excellent Performance on Undergraduate Education" by the Ministry of Education in 2005 and "the Most Internationalised University" by Hubei Provincial Government in 2010.

\section{Language policy}

Language policy is a complex construct. In a narrow sense, it relates to 'officially mandated' statements, rules, and regulations made by authorities in society regarding language forms, functions, uses and acquisition (Shohamy 2006, Spolsky 2012: 3). It is closely associated with language planning, a term that was initially used to describe linguists' engagement with 'language problems of newly independent states' (Spolsky 2012: 3) and, later, is widely used to capture 'attempts to change languages, in terms of their forms and functions' (Wardhaugh and Fuller 2015: 368). The project of language policy starting with 'language problems' aligns with an assumed need for solutions and points to a linear process of 'goals', 'means', and 'outcomes' (Rubin 1971: 218). Since the term language planning was first used by Haugen (1959) to refer to language standardisation in Norway, a considerable body of literature (see e.g. Ricento 2006) has integrated language policy and language planning together to discuss broader issues regarding authorities' initiatives in managing grassroots users of language choices in society. Consequently, the term language policy and planning (LPP) is widely used. Alternatively, both language policy and language planning are also found to be used respectively in literature to represent this integrative approach. Language policy is thus understood in a broad sense to serve as 'the primary mechanism' for 'managing' and regulating 'language behaviours' in society (e.g. Shohamy 2006: 45).

In an even broader sense, language policy is used by Spolsky (2012) to define a whole field of research, which he summaries to have three interrelated components - that is, language practices, language ideologies, and language management. Specifically, language practices focus on grassroots users' language behaviours and choices; language ideologies focus on values ascribed to and beliefs about language choices or models among community members; language management focus on top-down process of regulating grassroots users' language use. The success or failure in language management can be reflected in language practice, while the match or mismatch between language management and language practice requires an understanding of language ideologies. As Spolsky (2012: 5) points out, 'a language law does not guarantee observance'. This is widely evident in nu- 
merous studies showing that actual language practice is often in conflict with explicit or implicit policies (e.g. Cogo and Jenkins 2010, Kroskrity 2000, Wright 2000). This framework points to the interaction between authorities and grassroots and that between language practice and language ideologies. Importantly, the framework does not position language management as one-way delivery of language regulations but leaves space for authorities' moderation of their strategies in response to changing situations.

This framework, however, has two major challenges in explaining the dynamics of language policy in China. One is the issue of how to assess the interaction between authorities and grassroots. It is difficult to draw a line between authorities and grassroots when one takes into consideration different levels of administration in China. For instance, education institutions can be considered as grassroots in a sense that they are mechanisms of national language policy. On the other hand, institutions in different areas of China have their language policies, which offer guidance for teachers and students to follow in their educational practice. For instance, different institutions provide English-medium instruction to students on different programmes according to available resources. The other challenge concerns how to assess the interaction between language practice and language ideologies. Needlessness to say that language ideologies are a complex construct and competing language ideologies can co-exist in a given context. Moreover, beliefs about languages are not sufficient to predict language practice and language practice does not necessary reflect certain language ideologies. As revealed in Wang's (2013) study of Chinese speakers' language perception, Chinese speakers value Chinese culture and identity, simultaneously aspiring to the social capital assigned to Standard native English. While their preference for Standard native English certainly relates to the benefit that Standard native English can offer, the focus on this link leaves the internal struggle unaddressed and thus overlooks the potential for language change. These challenges in understanding language policy in China suggest a need for an analytical tool that can address different levels of administration and competing language ideologies.

Ricento and Hornberger (1996: 419) consider LPP as 'a multilayered construct, wherein essential LPP components - agents, levels, and processes of LPP - permeate and interact with each other in multiple and complex ways as they enact various types, approaches, and goals of LPP'. This framework examines 'how language functions within broader sociocultural contexts' that can be usefully divided into three layers, that is, national, institutional, and interpersonal levels (Ricento and Hornberger 1996: 408). As a multilevel model of analysis, it has strength in explaining various processes of language policy — such as formulation, implementation, evaluation, and feedbackfrom one level to another. It also allows for insights into language ideologies in and across different levels, as well as language policy-related activities and initiatives in and across different levels. The concept of agents acknowledges the roles of state governments, institutions and individual practitioners in the development of language policy. By discussing English language teaching (ELT) professionals' role in the interpersonal level of language policy, Ricento and Hornberger (1996) problematise the assumption that language policy is irrelevant for ELT professionals and reveal that ELT professionals can contribute to the reinforcement of or resistance to language policies, so as to have impacts on social transformation. It is not difficult to see the applicability of their discussion of ELT to other different disciplines. Language choice that teachers make in classrooms, the way that teachers use language for the purpose of teaching, and teachers' feedback on student works which are communicated in certain language forms are all ways of teachers' engagement with language policy, although teachers might not realise their impacts on the process of language policy. 
Recent work on English as a lingua franca (ELF) offers implications for language policy research. As evident in Spolsky (2012), conventional approach to language policy tends to focus on sociolinguistic issues tied to nation-state based speech communities. It follows that researching language policy in response to globalisation proceeds from the premise that as Seidlhofer (2011) observes, 'English is English is their English'- that is, national language of native English speaking nations. ELF research reconceptualises English in relation to community, identity and culture. Within the ELF framework, English is accepted as a chosen medium of communication in multilingual community of practice and used by its speakers for their purposes of constructing identities that are not confined to native English speaking cultures. To put it differently, the diversity of English deserves consideration in language policy research from an ELF perspective, given its significance for ELF users who are from different cultural backgrounds than native English backgrounds. In light of this, the discussion of language policy based on an ELF perspective engages choices of and attitudes towards different Englishes. For instance, Seidlhofer (2003) discusses language policy in the European Union (EU) and suggests that 'what English' or 'which English' should be considered, rather then simply regard English as a problem for multilingualism without critically understanding what or which English is causing problems. In the same vein, Cogo and Jenkins (2010) identify a mismatch between language policy and language practice in EU and argue that language policy should address the sociolinguistic reality of ELF. Recently, Jenkins (2014) has examined language policy in an international university and revealed that ELF is not reflected in the university's language policy despite the prominence of ELF in international academic communities.

Based on the above discussion, I adopt a multilevel analytical framework and examine what Spolsky (2012) labels as three component of language policy in and across national, institutional, and interpersonal levels respectively in order to understand policies about language forms, function, use, and acquisition oriented towards international students in Chinese higher education. Given the focus on international students in higher education, language acquisition is extended in this paper to associate with language support in general, as international students in higher education might have already developed some language proficiency to cope with disciplinary studies and language acquisition planning might be not appropriate for them. Apart from different language choices, I am interested to know whether the diversity of English operates in the processes of language policy, given the implication of ELF for language policy in the sociolinguistic context of globalisation.

\section{Methodology}

This study first examines descriptions of language policy oriented towards international students in higher education across China. It then explores the operation of language policy at institutional level by focusing on the case study of a Chinese university of which one classroom is further investigated in order to understand language policy at interpersonal level. For these purposes, I examined language policy descriptions provided by national government and various governmental agencies. In addition, the case study involves document analysis, classroom observation, and interviews, three of which allow for data triangulation.

Document analysis is a direct way of examining policies that are explicit. With document analysis, I investigated the university website, programme brochures, staff performance evaluation documents, university advertisements, university bulletin boards, university materials for international recruitment, and so on, in order to examine explicit and implicit language policies in education for international students. Classroom observation as a significant method of evaluating the implementation of programmes promoted or planned (e.g. Kerr, Kent, and Lam 1985) provides opportunities to understand the convergence or divergence between policies from above and practices at grassroots 
level in terms of language choices. With classroom observation, I looked for evidence of language choices and the nature of language practice in real life teaching and learning. The observed class group included 14 first-year international students who were all recruited by the university from Bangladesh. Altogether nine hours of classroom observation in six sessions altogether were video recorded with their permission. Interviews were adopted to understand how teachers as agents of language policies engaged the operation of language policy. With interviews, I was interested not only in what interview participants explicitly said about language practice and choice, but also in how they said about their language practice and choice to reveal implicit language ideologies. Four Chinese teachers were interviewed. Each interview lasted between 45 minutes and 75 minutes, depending on the participants' willingness to communicate and the information that they would like to share with the researcher. Interview participants were recruited among Chinese teachers on various disciplinary programmes for international students, such as microbiology, hydropower and economics, operations management, and Chinese culture. This study focuses on Chinese teachers for two reasons. First, Chinese teachers are the majority of teaching staff in Chinese higher education. The study of their language beliefs and practice will help to offer reference to Chinese higher education to a large extent. Second, language ideologies are often related to cultures and sociohistorical contexts (see e.g. Schieffelin, Woolard and Kroskrity 1998). It is constructive to focus on Chinese teachers who have shared cultural and sociohistorical backgrounds rather than include teachers from different backgrounds.

\section{The study}

The study reveals a great discrepancy between international students-oriented language policy at national level and language practice at interpersonal level, with language policy at institutional level taking a mediating position. Where language policy from the above promotes Chinese medium instruction (CMI) as necessary, and offers corresponding measures to enable CMI, English is used and treated as essential in actual classroom interaction and disciplinary studies. The university explicitly echoes the national policy in terms of the value of Chinese and provides Chinese support. However, it simultaneously acknowledges the need for English on international programmes and implicitly runs programmes where English is actually used as a primary medium of instruction.

The surface discrepancy is associated with the challenges faced up by lecturers on international programmes in terms of their professional identities. With English as a necessary medium of instruction in learning and teaching activities, the use of English has impacts on lecturers' work efficiency and teaching styles. Programme convenors fail to match staffing and disciplinary needs given a focus on the criterion for who can teach in English. The challenges thus point to a need for language support for lecturers. However, no English language support is mentioned in various levels of language policy. The solution to the challenges is expected to be developing international students' proficiency in Chinese.

What follows presents data to illustrate the points made above.

\section{Language policy across China}

An overview of language policies across China divides language policies in four categories ${ }^{1}$. The first category includes explicit policies to manage China's minority ethnic groups' use of language

\footnotetext{
${ }^{1}$ Acknowledgement to Professor Quufang Wen (文秋芳) from the National Research Centre for Foreign Language Education, Beijing Foreign Studies University, for pointing out the four categories in reviewing my draft of the paper.
} 
in education. The second category focuses on Chinese students' acquisition and use of languages including Chinese and English - in education. The third category addresses international students who come to China to study Chinese language and culture. The last category is concerned with international students who come to China to study content subjects. This paper is focused on the last category, though, as the data will reveal, language policies in this respect are yet to be developed. Analysis of official documents and public announcements in mass media, which address both international students and Chinese institutions in China at large, reveals a few major themes in language policy across China. I present data to illustrate each theme below.

First, Chinese is explicitly designated to be a primary medium of instruction oriented towards international students in various policy documents. The Study in China website lists altogether 50899 programmes oriented towards international students, including 47285 programmes through CMI and 6870 programmes through EMI. The Chinese Service Center for Scholarly Exchange is subordinate to the MoE and provides the following information for international students who are going to pursue studies in China:

Chinese is the major teaching language for International students in Chinese universities. Books, periodicals, and reference materials in university libraries and archives are mostly in Chinese. International students have to have a command of Chinese to a certain level in order to finish their studies smoothly.

The MoE (2014) issued the Public Letter Seeking Public Suggestions for Regulations for Institutions Recruiting and Developing International Students. The draft Regulations attached with the letter emphasised the position of the MoE on the medium of instruction to international students, as seen below:

Chinese should serve as institutions' primary medium of instruction in cultivating international students. Institutions can provide necessary Chinese-learning support to those international students whose Chinese proficiency is not high enough to cope with their studies. (my translation)

Second, along with CMI, there are Chinese tests, Chinese learning support, and incentives for Chinese proficiency development available to international students. As evident in the previous extract, the $\mathrm{MoE}$ is determined to promote $\mathrm{CMI}$ and to address possible challenges in implementing CMI among international students. In the Ministry of Education International Cooperation and Communication Office's Regulations for Chinese government studentship (China Scholarship Council 2008), Chinese proficiency is particularly treated as an advantage in competing for various studentships, which are applicable to undergraduate and postgraduate studies, general further education programmes, and advanced further education programmes.

Applicants for Chinese government studentships should in principle have appropriate proficiency in Chinese (except those who study Chinese and those who attend foreign languagemedium programmes). For those who do not have appropriate Chinese proficiency and cannot cope with their studies, up-to-two academic years of Chinese learning can be arranged with institutions. Their studentships will be extended to cover the time in their Chinese language learning, their undergraduate and postgraduate programmes. (my translation) 
It can be inferred that the MoE encourages international students to pursue Chinese proficiency by offering incentives and support rather than rejecting international students who have not proficiency in Chinese. This is confirmed in the analysis of documents required in applying for Chinese government studentships, as no document related to Chinese language proficiency is required to be submitted. However, in the further information provided in the Questions and Answers section of the scholarship application, it is noted that international students are required to pass the host institutions' Chinese language course in order to move on to disciplinary studies. This shows the MoE's insistence on CMI.

Third, English is often treated as an additional medium of instruction on some programmes oriented towards international students, and institutions have autonomy in deciding their own policies on EMI. This is made explicit in the MoE's draft of Regulations for Institutions Recruiting and Developing International Students:

Higher education institutions, if conditions permit, can offer disciplinary programmes oriented towards international students where English or other foreign languages are used as mediums of instruction. International students who participate in foreign-language-medium higher education diploma programmes can write their dissertations in corresponding languages used as the medium on their disciplinary programmes. Whether the same languages should be used for degree dissertation abstracts and vivas can be decided by institutions or departments providing the programmes. (my translation)

English is not made as noticeable as Chinese in China's higher education oriented towards international students. Where English is mentioned in language policies, it is mentioned only in passing. For instance, China Scholarship Council (2012) describes the MoE's position as follows:

We will try to build brand names of our courses, optimise course structure and develop a course system more attractive to international students. We will support higher education institutions to build their own brand-name programmes delivered in Chinese and to offer a certain amount of degree programmes in English. We will provide intensified support to the degree programmes with Chinese characteristics and internationally comparative advantages, to improve the international competitiveness and impact of higher education institutions.

Finally, it is hard to find evidence of language support for English-medium instruction. In comparison with language support for CMI, English support appears to be completely overlooked. Noticeably, all information offered on the websites oriented toward international students is accessible in English. An interesting question arises as to whether the Chinese government sees international students as language users who have no need for language support. As the MoE suggests that Chinese institutions have their autonomy in deciding the policy and practice of EMI, this question deserves further investigation in institutional and classroom operation.

\section{Language policy at institutional level}

Despite the fact that the global spread of English makes the role of English as a lingua franca (ELF) self-evident in international academic communities (Jenkins 2014, Mauranen 2012), the university's documents and website adhered to the use of Chinese for the purpose of delivering its messages as an international university. Much information is provided in Chinese but very limited use of English 
on the university website. Nevertheless, the Study in China website provides information on this university and includes links to the university's relevant sections in English. This emphasises the link between the university and Chinese higher education. As a member of Chinese higher education system, the university lets international students get access to it via official channel of Chinese education.

In line with language policy across China, the institutional language policy continues to regard Chinese as significant in international communication. The university provides Chinese language tests and expects international students to obtain certificate of Chinese language proficiency. The significance of Chinese for international students is indicated in the introduction to Chinese language programme oriented towards international students, as seen in the booklet:

With the rise of China, the fervor of learning Chinese occurred throughout the world and Chinese is expected to become more and more important in international communication.

The university' language policy accepts both Chinese and English as mediums of instruction but does not treat Chinese as a medium of instruction that can work on its own in international programmes. For example, the programme booklet, entitled Prospectus for International Students and designed for the purpose of recruiting international students, reads explicitly that the language used for instruction is 'Chinese/English' on most programmes oriented towards international students, for example, civil engineering, hydraulic and hydroelectiric engineering, tourism management. One and the only international programme entitled Bachelor of medicine and Bachelor of Surgery labels English as the only medium of instruction. Students participating in this programme have been mostly Indian and Nepalese students since the university was authorised to recruit international students by the Ministry of Education in China. As statistics provided in the programme show, "more than 250 Indian students and 100 Nepal students' who received degrees on this programme 'took part in their own countries' examination of doctors' qualification, of whom about 180 Indian students and $90 \mathrm{Nepal}$ students passed at the first attempt'. It is fair to say that international students on this programme grasped disciplinary knowledge through EMI and received good disciplinary support for their professional development. By contrast, not a single programme has Chinese as a sole language of instruction for international students.

No evidence is found to suggest that the university provides English support to either students or staff on given EMI programmes. Neither explicit specification was found regarding how language should be used. Examining the use of language in documents or university websites shed some lights on the expectation of the nature of language use in policy level. Some usages of English are not native-like. Here are two examples drawn from the Prospectus for International Students as given below:

There are 94 teaching and research staff, among which 11 are doctoral supervisors, and 34 are professors.

Faculty of tourism management serves to regional tourism development as its own mission, actively contacts tourism enterprises and administrative agencies...

It is necessary to note that the international office of the university was responsible for compiling and approving documents oriented towards international readers. The international office hired native English speaking employees and had a network in the College of Foreign Languages where 
there were some native English speaking teachers. Apparently, the persons who were involved in the production of this booklet did not get the documents checked in terms of native-likeness, although there was access to native English speakers who could proofread to achieve native-like production. A possible interpretation of this finding is that the international office was happy with the version of English that they produced.

\section{Language policy at interpersonal level}

Examination of language policy at interpersonal level reveals a different picture in terms of language choice, language use, language challenges, and language ideologies.

\section{Language choice}

English is a popular and necessary language choice in classroom communication between Chinese teachers and international students, whereas Chinese is rarely used in classrooms. Four interviewed teachers - referred to as T1, T2, T3, and T4 respectively - shared the view that English was necessary for international programmes oriented towards international students. Their comments are as follows:

T1: English is a bridge.

T2: I can only teach them in English.

T3: We communicate in English, although they could mix a few Chinese words in their utterance.

T4: I use English in class. The students are required to learn some Chinese, but their Chinese is not enough for them to manage the programme.

Classroom observation confirmed that English was an important factor in evaluating the quality of teaching. At the end of one session in the beginning of a semester, T2 asked students for their feedback on the course in order to see whether anything should be changed or improved for future sessions. Students were giving positive feedback. Interestingly, students — referred to as S1, S2, .. Sn in data presentation - treated the invitation for feedback as a question and offered their views on T2's teaching. Their views were likely to concern English.

S1 (smiling): You're a good teacher. Your English is good. Your lecture is interesting.

S2: er, your lecture is good. I can understand your lecture.

S3:Yes, your English is good. I can understand.

S4: Yeah, it is good, it is good.

S5: Yeah, it is good to study in English.

\section{Language use}

Regarding how English is used interpersonal level, lecturers seem to be happy with the interactions between them and international students. The interviewed lecturers show consensus that they focus on meaning-making and do not bother to analyse forms of English in classroom interaction or in assessment. Importantly, if I as the researcher - referred to as $\mathrm{R}$ in data presentation - did not explicitly ask how they compare their English with native English, none of them would even mention native English or native English speakers. In my conversation with T3, for example, it took quite a few turns to refer her to native English, but she soon dismissed the reference.

\section{$\boldsymbol{R}:$ How do you think about your communication with international students?}


T3:I-—think,good@verygood@

R: So, do you communicate with each other well? Or do you have difficulties?

T3: Yeah, we communicate well. We don't have difficulties. They said I'm a good teacher@

R:Oh,Okay@howdoyou think aboutyour English? How do you think about their English?

T3: I think@my English is good. They are all good at English. If they are not good at English, they can't come here and study.

R: Do you mean your English is native-like and theirs-

T3: -@ [shaking head] no, of course not native-like. But we communicate well. Nobody is native-like. But their English is still good.

Classroom observation confirms classroom interactants' focus on how to get the job done. They do not confine themselves to English, although English plays a dominant role in classroom communication. What García and Li Wei (2014) describe as translanguaging is observed in the class settings. Students make jokes with each other with a few Chinese words inserted in their English. For example, ‘很好' (very good), “没问题' (no problem), ‘是这样'(that is it). The lecturer encourages the students to help each other by using their first languages to explain difficult points. Here is an extract from the observation data:

(T2 noticed that one student was a bit confused with the idea that he just passed on)

T2 (looking at S1 who is next to the confused student): Could you explain to your friend what is operational cost?

S1: (smiling and hesitating)

T2: You can explain in Bangladesh.

S1: (still hesitating)

T2: Come on, help your friend, you can tell him in Bangladesh

S1(smiling at the confused student): I want to explain it in English

T2: Oh, ok

\section{Language challenges}

The use of English, while necessary on international programmes, is viewed by lecturers as problematic in two ways. In one way, lecturers feel less efficient in teaching through English than through Chinese. Specifically, preparing EMI lectures is found to take a longer time than preparing Chinese medium lectures; EMI changes lecturers' styles in delivering disciplinary knowledge and undermines their professional identities. These complaints echo those identified in EMI research in some other non-native English speaking contexts (e.g. Doiz, Lasagabaster and Sierra 2013). For instance, T1 describes her experience of EMI teaching as follows:

T1: As a teacher specialised in science and technology, I know only how to communicate in the scope of my discipline, I'm still far below the level that English can be used to communicate in cultural perspective [...] If I taught Chinese students, I would tell some stories, jokes, and tell them where they can go and find, for example, yeast, and what they can try to do with yeast by themselves [...] If I taught a two-class session, I would have spent two days preparing for the session. I would have made a lot of effort [...] I would need to read the textbook for a few times and rehearse so that I could give the lesson smoothly, then I would have to prepare PowerPoint slides very well, so that I would not forget what to say when I was teaching, wow, I can't forget what to say, a lot of hassle. 
In another way, the coordination of EMI programmes encounters a staffing issue, which mainly concerns the conflict between language competence and disciplinary expertise. This conflict is explicitly expressed by $\mathrm{T} 2$ :

T2: I can teach in English, but what I can teach in English is not my decision, the program is planned by the program leaders [...] then I was chosen to teach on the EMI course [...] There're actually not many teachers who can use English to teach in this university. If all teachers could teach in English, there would have been different criteria for the selection of course teachers. English would not necessarily have been considered as the major criterion. Because many teachers aren't selected no matter how strong they are in their subjects and how suitable they are for the courses, they are not selected only because they can't teach in English.

No evidence is found of helping EMI lecturers to tackle the challenges they face, except that international students are expected to develop sufficient proficiency in Chinese so that they can participate in CMI one day. This hope aligns with the national language policy oriented towards international students and university policy for international education. T1 is very keen in supporting this idea.

T1: When the students first come to the university, English is a bridge through which the students can communicate with Chinese teachers and students and local people. But later, as you (the students) are in China, you (the university) still need to promote Chinese culture, right? Otherwise, you come to China and learn half-cooked English? What for? Is that meaningful? Not at all. [...] English can only play the 'bridge' role, you'll still need to learn Chinese at the end of the day. On the other hand, you need to identify yourself as distinct. If so, you need to teach Chinese. Because you can never identify yourself as distinct in English. Native language is incomparable, right?

T1 recognises the pragmatic value of English for communication when Chinese teachers and international students do not share other languages. However, she considers Chinese as important for identity reason and sees university as mechanism of promoting national culture. Her point that a person can only learn 'half-cooked' English in China reveals her belief that China is not a place where good English is resourced. Obviously, she is subject to a traditional view of language as defined on the basis of national boundary (e.g. Blommaert 2010, Pennycook 2010, Seidlhofer 2011). In addition, her belief that English is for transition purpose while Chinese will take over ultimately seems to offer her good reason to be optimistic that the issue of English will be solved in a matter of time.

\section{Language ideologies}

Despite the complexity of the concept of language ideology (see e.g. Kroskrity 2000, Makihara and Schieffelin 2007), my approach to language ideologies in this paper follows Spolsky's framework of language policy and focuses on value ascribed by classroom participants to available language choices. By taking ELF research into consideration, I also look at an ELF-informed conception of language.

Conflicting language ideologies are visible at interpersonal level. Interviews and classroom observation point to the appreciation of English as a valuable choice for teaching and learning activities oriented towards international students. Other languages e.g. Chinese and Bengali are equally ac- 
cepted as useful in real life communication when they help to boost communicative effects. The attitudes contrast with the value exclusively attached to Chinese in language policy from the above. In response to challenges arise in using English for lectures, however, there is an emerging assumption that Chinese taking place of English can be a solution - though the feasibility of CMI in higher education for international students is a question that deserves further investigation in the future. The assumption aligns with the belief in the cultural and identity value of Chinese as well as the significance of Chinese for China. This reminds me of a traditional belief in China that Chinese learning as $t i$ (体, essence); Western learning as yong (用, utility) (Gao 2009). The belief that pragmatic value is attached to English and that cultural and identity value are attached to Chinese reiterates the link between language, culture, and nation in terms of geographical boundaries. On the other hand, there emerges a reclaimed ownership of English by international users of English in international settings. The use of English is focused on meaning making and translanguing is welcomed in classroom activities, where no evidence points to a concern with the reference to native English norms. The linguistic behaviour and emerging ownership pose challenges to the languagein-place paradigm (see Blommaert 2010). Thus, the conception of language is not consistent at the interpersonal level, though classroom participants might not be aware of the contradiction.

\section{Conclusion}

The study shows a policy vacuum with regard to EMI for international students in China. In contrast, there is comprehensive support for the development of Chinese proficiency from the national level to the institutional level, despite the limited use of Chinese in actual classroom practice. Thus, the policy vacuum is associated with three overlooked facts. First, there is a growing number of international students in China, whose language needs are not investigated but assumed. Second, there is increasing evidence for the role of ELF in international communication, which, however, is not represented in language policy. Third, EMI lecturers are needed in order to carry out teaching and learning activities oriented towards international students, but their language skills rather than disciplinary expertise are prioritised by programme managers.

The vacuum has two immediate effects. On the one hand, language management from above appears to be elusive and leads to classroom players' struggle, uncertainty, and lack of support. In this sense, improving international students' education is reduced to lip service. On the other hand, given no policy regarding how to use English in EMI education, EMI participants seem to have linguistic freedom and, as observed in the study, they indeed focus on meaning making in communication through English as medium. Nonetheless, the lack of legitimation for EMI in contrast with the strong support for CMI inevitably contributes to a linguistic hierarchy and emphasises the inclusiveness and exclusiveness of Chinese in China's higher education, which however conflicts with China's aim for internationalisation and its orientation towards international students. The policy vacuum needs to be addressed so as to develop Chinese higher education for international students in a healthy way and prevent harmful effects on linguistic diversity and on China's engagement in international community.

To address the policy vacuum, it is practically necessary to recognise the role of ELF in international academic communities and consider EMI support for both students and lecturers at both national and institutional levels, as directly suggested by this study. Theoretically, it is constructive to integrate an ELF research-informed conception of language in legitimising the use of English in Chinese higher education for international students. An ELF approach (see e.g. Jenkins 2015, Seidlhofer 2011, Mauranen 2012, Widdowson 2003) highlights the shifting ownership of English from native English speakers to global users of English, the changing perspective from deficit to differ- 
ence in English, the dislocation of language from geographically defined speech community, and the identification with English by non-native English speakers in ways that they have control of English. In light of this approach, English is becoming the language or language resource of Chinese speakers and of other first language speakers in the era of globalisation. Recognising this, Chinese authorities should give more attention to English in language policy in higher education that connects Chinese lecturers with international students. In terms of English use, the language practice that I have observed in classrooms and that has been described by lecturers in interviews, follows its own norms as opposed to pre-determined norms generated from native English speakers' speech communities. Thus, how English is used in real life classroom settings should be the starting point where bottom-up language policy process proceeds to influence decision making from above. Importantly, recognising how English is used helps to make lecturers focus on disciplinary content rather than how to produce good English. It is hoped that the legitimation of the use of English from this bottom-up approach will strengthen the link between language policy and language practice at different levels, will enable effective management of Chinese higher education oriented towards international students, and will create supportive learning and working environments for both students and lecturers.

\section{References}

Blommaert, J. 2010. The sociolinguistics of globalisation. Cambridge: Cambridge University Press.

Cogo, A. and J. Jenkins. (2010). English as a lingua franca in Europe: A mismatch between policy and practice. European Journal of Language Policy. 2.2: 271-294.

Doiz, A.,D. Lasagabaster, and J. M. Sierra 2013. English-medium instruction at universities: Global challenges. Bristol, Buffalo, Toronto: Multilingual Matters.

García, O. and Li Wei. (2014). Translanguaging: Language, bilingualism and education. Palgrave macmillan.

Gao, Y. (2009). Sociocultural contexts and English in China: retaining and reforming the cultural habitus. In: LO BIANCO, J., ORTON, J. \& GAO, Y. (eds.) China and English: Globalisation and the Dilemmas of Identity. Bristol: Bristol: Multilingual Matters.

Haugen, E. (1972). The ecology of language: Essays by Einar Haugen. Selected and introduced by A. S. Dil. Stanford, Calif: Stanford University Press.

Hu, G. and L. Alsagoff. (2010). A public policy perspective on English medium instruction in China. Journal of Multilingual and Multicultural Development. 31.4: 365-382.

$\mathrm{Hu}$, G. (2005). English language education in China: Policies, progress, and problems. Language Policy. 4.1: 5-24.

$\mathrm{Hu}$, W. (2001). A matter of balance - Reflections on China's foreign language policy in education. Foreign Language Teaching and Research. 4: 6-12.

Jenkins, J. (2014). English as a lingua franca in the international university: The politics of academic English language policy. London and New York: Routledge. 
Kerr, D., L. Kent and T. C. M. Lam. (1985). Measuring program implementation with a classroom observation instrument: The interactive teaching map. Education Review. 9.4: 461-482.

Kroskrity, P. (2000). Regimes of language: Ideologies, polities, and identities. Santa Fe, New Mexico: School of American Research Press; Oxford: James Currey.

Makihara, M. and B. Schieffelin. (2007). Consequences of contact: Language ideologies and sociocultural transformations in Pacific societies. Oxford, New York: Oxford University Press.

Mauranen, A. (2012). Exploring ELF: Academic English shaped by non-native speakers. Cambridge: Cambridge University Press.

Pan, L. (2011). English language ideologies in the Chinese foreign language education policies: A world-system perspective. Language Policy. 10/3: 245-263.

Pennycook, A. (2010). Language as a local practice. London and New York: Routledge.

Ricento, T. (2006). An introduction to language policy: Theory and method. Malden, MA: Blackwell Publishing.

Ricento, T. and N. Hornberger. (1996). Unpeeling the onion: Language planning and policy and their ELT professional. TESOL Quarterly. 30.3: 401- 427.

Rubin, J. (1971). Evaluation and language planning. In J . Rubin \& B. Jernudd (Eds.), Can language be planned? Sociolinguistic theory and practice, for developing nations. Honolulu: University Press of Hawaii. (pp.217-252)

Schieffelin, B., K. A. Woolard, and P. V. Kroskrity. (1998). Language ideologies: Practice and theory. New York: Oxford University Press.

Seidlhofer, B. (2003). A concept of international English and related issues: from 'real English' to 'realistic English'? Council of Europe.

Seidlhofer, B. (2011). Understanding English as a Lingua Franca, Oxford, Oxford University Press.

Shohamy, E. (2016). Language policy: Hidden agendas and new approaches. London and New York: Routledge.

Spolsky, B. 2012. The Cambridge handbook of language policy. Cambridge: Cambridge University Press.

Wang, Y. (2013). Non-conformity to ENL norms: A perspective from Chinese English users. Journal of English as a Lingua Franca 2(2), 255-282.

Wardhaugh, R. and J. M. Fuller. (2015). An introduction to sociolinguistics. (Seventh ed.). Wiley: Blackwell. 
Widdowson, H. 2003. Defining issues in English language teaching. Oxford: Oxford University Press.

Wright, S. (2000). Language policy and planning: From nationalism to globalisation. Palgrave Macmillan.

Zhou, M. and H. Sun. (2004). Language policy in the People's Republic of China: Theory and practice since 1949. Boston: Kluwer Academic Publishers.

China Scholarship Council. http://en.csc.edu.cn/Laihua/indexen.aspx.

Study in China: http://en.csc.edu.cn/Laihua/indexen.aspx.

China Scholarship Council. (2012). Plan for study in China. http://en.csc.edu.cn/Laihua/newsdetailen.aspx?cid=192\&id=1348. [Accessed 1 December 2016]

China Scholarship Council. (2008). The Ministry of Education International Cooperation and Communication Office's Regulations for Chinese government studentship. (教育部国际合作与交 流司关于中国政府奖学金的管理规定).http://www.csc.edu.cn/laihua/newsdetail.aspx? cid=191\&id=1347. [Accessed 1 December 2016]

MoE. (2010). The National Outline for Medium and Long-term Education Reform and Development (2010-2020). 国家中长期教育改革和发展规划纲要 (2010-2020年).http://www.moe.edu.cn/ publicfiles/business/htmlfiles/moe/moe 838/201008/93704.html. [Accessed 1 December 2016].

MoE. (2014). The Public Letter Seeking Public Suggestions for Regulations for Institutions Recruiting and Developing International Students (关于对《学校招收和培养国际学生规定》 (征 求意见稿 ) 公开征求意见的公告). http://www.moe.edu.cn/jyb xw fb/s248/201401/ t20140103_161795.html [Accessed 1 December 2016]

MoE. (2016). Statistics of international students in China in 2015. (2015年全国来华留学生数据发 布). http://www.moe.edu.cn/jyb_xwfb/gzdt_gzdt/s5987/201604/t20160414_238263.html. [Accessed 1 December 2016]

MoE. (Unknown). International education work. (留学工作) http://www.moe.edu.cn/jyb_sjzl/ moe_364/moe_302/moe_390/tnull_4560.html. [Accessed 1 December 2016] 